\title{
Teaching Reform of Physical Chemistry Experiment in Application- oriented Colleges
}

Shijing Zhan ${ }^{\mathrm{a}}$,Lianzhu Peng ${ }^{\mathrm{b}}$, Jingmei Lu ${ }^{\mathrm{a}}$, Tong-ying Feng ${ }^{\mathrm{a}}$, Bingzhi Guo ${ }^{\mathrm{a}}$, Wuqing Du ${ }^{\mathrm{a}}$, Xiaohong $\mathrm{He}^{\mathrm{a}}$, and Ling $\mathrm{Wu}^{\mathrm{a}^{*}}$

a School of Chemical Engineering and Materials Science, Beijing Institute of Technology, Zhuhai, China

${ }^{\mathrm{b}}$ School of Accounting and Finance, Beijing Institute of Technology, Zhuhai, China

*Corresponding author: Ling Wu, Master of Science, zhanshijing@163.com

\begin{abstract}
Based on the requirements of physical chemistry experiment and the characteristics of applicationoriented colleges, some suggestions for the teaching reform of physical chemistry experiment were proposed, including the cooperation between theory and experiment, using the teaching mode of subgroup alternating, reforming the teaching contents and teaching method, preparing the experiments with the assistance of the internet, constructing an evaluation system. By doing so, both the teaching performance of experiment and comprehensive ability of the students were greatly improved.
\end{abstract}

Key words: physical chemistry experiment; teaching reform; multi-level teaching of experiment; subgroup alternating; evaluation system

\section{Introduction}

Physical chemistry experiment is a significantly basic course of chemistry and chemical engineering, as it is a highly practical program which needs to use instruments to conduct experiments, and it is mainly theoretical study which verifies and explores physical property, chemical property and chemical reaction law. ${ }^{1-2}$ Physical chemistry experiment plays a key role in cultivating students' problem analysis and solving skill and innovation spirit. Along with development of modern technology, renewal of experimental instruments, continuous improvement of experiment technologies, and especially computer's capacity in fast and accurate processing of a large amount of Physical chemistry experiment data, the content, method and teaching mode of Physical chemistry experiment keeps progressing. How to train students to operate constantly renewal instruments and enable students to analyze and solve problem independently remains an important research topic of current experiment teaching reform. $^{3-5}$

Based on requirements of Physical chemistry experiment teaching this paper combined characteristics of application-oriented colleges, adopted various practices, established teaching mode of multi-level Physical chemistry experiment, ${ }^{6-7}$ and discussed reform measures of Physical chemistry experiment in application-oriented college. 


\section{Experimental and discussion}

\subsection{To emphasize close cooperation between physical chemistry experiment class and theoretical class}

Physical chemistry experiment has a huge effect on understanding and mastering theoretical knowledge of physics and chemistry, and the theories are foundation of experiment. Through analyzing and explaining the phenomenon and data results, the two become an organic whole. In the practical process, experiment class teaching must be under the charge of teachers who has teaching experience in physical and chemical theories. If it is limited by the actual condition, the teacher being selected must be equipped with a good foundation of physical and chemical theories, so as to realize close cooperation between Physical chemistry experiment class and theoretical class, and to lay talent foundation for multi-level experiment teaching. a)The content and schedule of experiment class must match with that of the theoretical class. Generally, it is required to open corresponding experiment only after finishing theoretical class, in order to verify theories and deepen understanding on theories by experiment and to provide good theoretical foundation for subsequent multi-level experiment teaching; b)The theoretical part closely related to experiment should be focused. While explaining theories that need students' further understanding, it is important to emphasize the correlation between experiment and theory; c)Inspire students' interest in the experiment in theoretical class and cultivate students' scientific literacy in experiment teaching. For example, while giving theoretical class, the teachers shall introduce historical background of theories and the ways to verify accuracy of theories; while in experiment teaching, the teachers shall explain less and ask more, guide students to grip the overall structure of experiment and to think over the details of experiment, in order to improve their scientific literacy.

\subsection{To adopt teaching mode of subgroup alternating}

In recent years, due to expansion of application-oriented colleges, the laboratory had to accommodate more and more students and the complement speed of laboratory, equipment and teacher team fell behind the speed of student growth. This led to great difficulty to arrangement of experiment teaching. Our research group worked out a set of subgroup alternating methods, to make full use of limited laboratory and teacher resource, so as to guarantee teaching quality as well as improve the capacity of laboratory.

Taking Physical chemistry experiment class in this year as the example, now our college has laboratory I and II, each of which can have two experiments at once, and each of the experiment can be equipped with six or seven sets of instruments. In a class, there are fortyeight students, which can be divided into four big groups to correspond to four experiments. Each group has twelfth students (two students share one set of instruments). In traditional teaching mode, teaching task of 1 experiment for the whole class will take four lessons. In the subgroup alternating way, the experiment resource can be utilized more efficiently. Refer table 1 for specific details: divide a class of 48 students to four groups, which are A, B, C, and $\mathrm{D}$, each of which has 12 fixed students. One laboratory will offer two experiments and teacher A and B will take charge of experiment teaching of the two laboratories respectively. In the first week, group A does experiment 1 in laboratory I, and group B does 2 in laboratory I, group C does 3 in laboratory II, group D does 4 in laboratory II. In the second week, group A and $\mathrm{B}$ switches with each other, when group $\mathrm{C}$ and $\mathrm{D}$ switch with each other. In such 
alternating way, teaching task of one experiment of one class can be finished in one week. In the meantime, since the teachers are fixed in the corresponding laboratory, the teachers' professionalism in experiment teaching will be improved. This alternating way greatly improves the capacity of laboratory, enhances teachers' professionalism, and lays a good laboratory foundation for further multi-level experiment teaching.

Table 1 - Schedule of physical chemistry experiment

\begin{tabular}{|l|l|l|l|l|}
\hline Member grouping & $\begin{array}{l}\text { Experiment, } \\
\text { classroom } \\
\text { (First week) }\end{array}$ & $\begin{array}{l}\text { Experiment, } \\
\text { classroom } \\
\text { (Second week) }\end{array}$ & $\begin{array}{l}\text { Experiment, } \\
\text { classroom } \\
\text { (Third week) }\end{array}$ & $\begin{array}{l}\text { Experiment, } \\
\text { classroom } \\
\text { (Fourth week) }\end{array}$ \\
\hline A (member list) & 1 (laboratory I) & 2 (laboratory I) & 3 (laboratory II) & 4 (laboratory II) \\
\hline B (member list) & 2 (laboratory I) & 1 (laboratory I) & 4 (laboratory II) & 3 (laboratory II) \\
\hline C (member list) & 3 (laboratory II) & 4 (laboratory II) & 1 (laboratory I) & 2 (laboratory I) \\
\hline D (member list) & 4 (laboratory II) & 3 (laboratory II) & 2 (laboratory I) & 1 (laboratory I) \\
\hline
\end{tabular}

\subsection{To reform teaching content and methods}

At present, current mainstream experiment teaching mode is teacher-oriented mode; most colleges adopt it since it is easy to be implemented. The mode's teaching objectivity is to make students verify learned theoretical knowledge through experiments, ${ }^{8}$ but it has shortcomings like low efficiency, easy-copying, and not effective in inspiring students' enthusiasm, etc. As a result, it is hard to apply this mode to realize the goal of training highquality “applied” talents. To improve talents' cultivation quality, our research group conducted various researches and practices on educational reform. Based on the actual condition, we applied multi-level Physical chemistry experiment teaching mode. ${ }^{5}$

In multi-level experiment teaching, teaching content and evaluation are divided into several levels. For example, according to the difference of experiment content and to-be-solved problems, same type of experiments are designed to multi levels, such as basic experiment, improving experiment, open experiment, etc. Basic experiment refers to traditional and relatively easy verification experiment. Improving experiment indicates the kind of experiment aims at improving students' self-learning ability through increasing experiment difficulty by changing chemicals, instruments, methods and so on based on the basic experiment. In open experiment teaching method, while providing only basic experimental conditions such as experiment name, list of experiment instruments, and list of chemicals, etc., the student have to search for information to determine experiment method, steps, and cautions, etc. according to experiment objectivity, and submit the list of needed instruments and chemicals to relevant experiment management personnel, and at last, complete experiment operation, data processing and report submission, etc. In the whole experiment process, the teacher is responsible for communicating about preparation of experiment, and ensuring timely arrival of instruments and chemicals, solving and supervising problems in students' operation, and making evaluations on experiment condition. In this process, difficulty coefficients are set according to experiment difficulty, proper assessment is given through corresponding coefficients in the last rating process. Taking electrochemical experiment as the example, the options for the students are three experiments of three different coefficients. The basic experiment is measurement and application of electrodynamic force (there are detailed reference to experimental instruments and process on 
textbook, so the difficulty coefficient is 1); the improving experiment is measurement of ionic migration amount (additional requirement: it is not allowed to use the calibrating method of $\mathrm{Cu}^{2+}$ ionic concentration on textbook, so the difficulty coefficient is 1.25); the open experiment is plating of non-metallic materials (its difficulty coefficient is 1.5, when the laboratory provides list of available instruments and chemicals, and the students prepare experiment plan, bring basic materials and necessary materials for the experiment, etc.). Multi-level experiment teaching mode makes effective classification according to students' wish and learning capacity, and realizes "teaching students in accordance with their aptitude". It effectively improves students' learning enthusiasm, motivates and inspires students' learning initiative and activity, cultivates students' ability of independent thinking and exploration.

\subsection{To encourage students to use computer and online resource to conduct experimental preparation, and experimental data processing}

Comparing with students in key colleges, students in application-oriented colleges perform poorer in self-learning and learning initiative. For them, the traditional Physical chemistry experiment preparation method cannot receive good effect, and lead to long experiment time and a bad effect. Traditional experiment preparation method refers to that student completes preparation for experiment objectivity, principle, equipment, steps, caution and other items through reading prescribed textbooks. In this way, students work more by pen than by brain, and it is common that students copy books and have not obvious result. Especially, due to lack of perceptual knowledge about experimental instrument and equipment and operation, the preparation result would be quite poor. Therefore, the experiment teacher has to spend a lot of time on introducing principles and use of instruments and equipment. For experiment that is related to more equipment or relatively expensive instruments, the teacher will take more time on introducing. In addition, such preparation method will easily cause passivity of some students, who will wish the teacher to guide instruction during class rather than spend time on experimental preparation, so that the preparation is even worse. Gradually, this becomes vicious circle. ${ }^{1}$

In fact, nowadays, when computer and mobile terminals are universal and internet resource are relatively developed, teachers and students shall fully and rationally apply internet resource to work on experimental preparation.

To achieve good effect of previous preparation, the research group mainly made two things. Firstly, our college opened the course of Application of Computer in Chemistry and Chemical Industry, which is a prerequisite course of Physical chemistry experiment, to make students understand how to use computer and internet to inquire information, edit document, process data, and complete thesis. Secondly, by combining actual condition of experimental teaching, in preliminary process of building quality courses, relative materials of experimental teaching was put on the school network, effective links of some relevant websites were established, in order to establish an experimental preparation platform and to provide convenience for students to prepare for experiments. The students are encouraged to use websites like Baidu.com, Google.com, Youku.com, Tudou.com and so on to inquire use instruction and operation videos of instruments, and to look for experimental information and videos by entering relevant quality course websites through links. In addition, the students encouraged 
to make experimental operation to FLASH by computer software, to form electronic preparation report or experimental report, which can be included in experimental report level rating system. In this process, materials for experimental learning and reform can be accumulated. Through such preparation, students not only comprehends relevant experimental principle and steps, and perceptually understands structure, principle, operation method and cautions of relevant instruments and equipment, so that they greatly save experiment time and improves preparation effect, and lay good preparation foundation for experiment teaching. In the meantime, the students can practice the skill of internet searching, obtaining useful information, and summarizing, which is very important in the era of knowledge-based economy.

Physical chemistry experiment requires students to be equipped with good data processing ability, such as linear fitting processing, drawing tangent, calculating gradient, and intercept, and so on. In the process of Physical chemistry experiment teaching, the students are required to give up the previous artificial drawing that is time-consuming and effort-consuming and has a high measurement error, and to adopt computer software to process experiment data to improve work efficiency and data accuracy. The course Application of Computer in Chemistry and Chemical Industry has already required students to master Origin and Excel and such common data processing and graphics software for Physical chemistry experiment skill fully. ${ }^{9-10}$ Application of software on data processing effectively reduces subjective error, rationalizes the processing result, and obtains normalized graphic. Improvement of data processing skill lays a good foundation for students to engage in scientific research in the future. In addition, during practices and reform of Physical chemistry experiment teaching, we found that students can have significant improvement of experiment report by mastering computer software to process experimental data.

\subsection{Enhance experiment evaluation efforts, encourage students to analyse and propose suggestions, in order to promote quality of experiment teaching}

Fair and rational experiment evaluation method is an important factor to guide students' independent study and to improve teaching quality of experiment class. Establishment of a set of complete, detailed, fair and accurate evaluation system is a significant link that is directly related to developing experiment teaching content and realizing experiment teaching objective. 11 Through years' teaching practice, to overcome the shortcoming of determining only by experiment report and to radically change the evaluation method that gives experiment grade only based on experiment report, we established the mode of whole-course evaluation. Firstly, the students shall be required to enter the laboratory and submit preparation report 10 minutes before the experiment starts. Secondly, before the formal experiment, the teachers shall ask questions to guide students to positive thinking status, focus on students' questions about the experiment and on major tatters, evaluate students' experiment preparation grade according to students' preparation report and question answering condition. The preparation grade is 20 in total. Thirdly, in the experiment process, the teachers shall pay attention to students' ability of experiment operation and data record, emphasize on conditions like reagent preparation, standard operation of instrument, selection of experiment method, and independent operation, etc. In the experiment process, the students shall be allowed to make mistakes to some extent, pay attention to guide the students to discover problems, give instruction and correction when 
necessary, and reduce students' psychological dependence. The grade of this part is 20 in total. Fourthly, after completing the experiment, the students shall wait the teachers to sign on the preparation report notebook and leave the laboratory, in order to avoid that students copy from each other or change data; the students are required to use software like Excel and Origin to process data and write experiment report; when the teachers mark the experiment report, they shall pay more attention to the part of data processing and discussion around experiment, which include analysis and explanation of experiment phenomenon, difference between experiment result and theoretical conclusion, main factors influencing experiment result, reflection on experiment, etc. The grade for this part is 60 in total. The grade 60 of experiment report shall be calculated through multiplying the base 40 by corresponding coefficient according to difficulty degree. The total grade of basic experiment (its coefficient is 1.0 ) is 40 . The total grade of improving experiment (its coefficient is 1.25 ) is 50 . The total grade of open experiment (its coefficient is 1.5 ) is 60 . The reason for such setting is to guide students to select more-demanding experiment (open experiment) initiatively. The students' self-learning ability, operation skill, data processing ability, problem analysis and discussion ability, reporting skill are comprehensively evaluated according to experiment difficulty, preparation status, experiment condition, and experiment report.

\section{Conclusions}

To sum up, through continuous reform, exploration and practices, by innovating teaching content, teaching mode and evaluation method, a multi-level experiment teaching mode was established and received significant teaching effect. However, teaching reform is a long-term and hard work, confronting with continuous new problems, so that we need to study, explore and practice steadily.

\section{Acknowledgements}

The authors gratefully acknowledge the financial support of Fund for Excellent Young Scholars of Guangdong, the Research Development Fund of Beijing Institute of Technology, Zhuhai (GrantNo. 2012JS08), the Quality Course Construction Project of Beijing Institute of Technology, Zhuhai (GrantNo. 2014003Y), and teaching Reforming Project of Beijing Institute of Technology, Zhuhai (GrantNo. 2014002J) .

\section{References}

1. E.N. Chen, Z.X. Hang, L.L. Wang, et al. Reform and practices in open experimental teaching of physics and chemistry, Experimental Technology and Management, 28(10) (2011) 125-126.

2. L.H. Gan, L.W. Chen, J.L. Qian, et al. A second thought about multi-level physical chemistry experiment teaching. Research and Exploration in Laboratory, 21(6) (2002) 8-9. 
3. H.C. Ge, S.W. Liu, R.Y. Jiang, et al. Cultivation of innovation ability in physical chemistry experiment teaching. Research and Exploration in Laboratory, 25(11) (2006) 1421-1422.

4. D.H. He, Y. Ma, et al. Development trend of and reform exploration in physical chemistry experiment teaching. Experimental Technology and Management, 23(3) (2006) 13-15.

5. X.G. Hu, D.F. He, X.H. Li, et al. Exploration and practices in research physical chemistry experiment teaching mode. Research and Exploration in Laboratory, 28(10) (2009) 133-135.

6. H. Li, X.B. Zhang, Z. Jin, et al. Exploration in reform of physical chemistry experiment teaching in local colleges. Research and Exploration in Laboratory, 30(10) (2011) 114-115.

7. X. Li, X. Ye, D.N. Chen, et al. To improve students' scientific literacy through reforming system of physical chemistry experiment teaching. Guangzhou Chemical Industry, 39(14) (2011) 154-156.

8. J. X. Yang, Z. Liu, Y.H. Zhou, et al. Application of excel and origin in data processing in physical chemistry experiment. Journal of Xi'an University of Arts \& Science (Natural Science Edition), 12(4) (2009) 122-124.

9. J.H. Yi, H. M. Mo, F.Z. Gong, et al. Data processing in physical chemistry experiment by origin software. Research and Exploration in Laboratory, 28(8) (2009) 56-59.

10. E.L. Zhao, H.Y. Min, Y.F. Shi, et al. Exploration in construction of evaluation system for physical chemistry experiment program. Journal of Higher Correspondence Education (Natural Science Edition), 24(1) (2011) 9-10.

11. L.N. Zhao, X. Li, Y.G. Ren, et al. To develop physical chemistry experiment teaching by the orientation of cultivating students' skill. Experimental Technology and Management, 32(3) (2015) 196-198. 